\title{
Reduction of exercise capacity in children from summer to winter is associated with lower sporting activity: a serial study
}

\author{
Jan Müller', Birgit Böhm', Julia Elmenhorst' ${ }^{1}$, Christiane Barta' and Renate Oberhoffer ${ }^{1}$
}

BACKGROUND: Declining activity in children over the past decades is thought to be one of the main risk factors for an early development of exercise intolerance and obesity. Taking this background into account, this prospective study investigated the seasonal change of children's physical activity and its association with objective measures of exercise capacity.

METHODS: A total of 96 children from two schools in Munich (42 girls, age $12.4 \pm 0.8$ y) underwent a cardiopulmonary exercise test (CPET) and an assessment of their daily activities (school sport, club sport, leisure sport) twice. Baseline testing was conducted in summer 2011. Follow-up examination was performed during winter 2012.

RESULTS: From summer to winter, self-reported sporting activity decreased from $10.6 \pm 4.1$ to $8.5 \pm 4.3 \mathrm{~h} / \mathrm{wk}(P<0.001)$ as school sport $(P<0.001)$ and leisure sport activities $(P=0.002)$ decreased, but the activity associated with club sport did not $(P=0.700)$. In parallel, peak oxygen uptake $\left(\mathrm{VO}_{2}\right)$ declined from $102.0 \pm 17.5$ to $96.9 \pm 17.9 \%$ of predicted $(P<0.001)$. This decline in $\mathrm{VO}_{2}$ was associated with a reduction in overall sporting activity $(r=0.234 ; P<0.032)$.

CONCLUSION: Enhancing sporting activity in children during winter might be important to maintaining their exercise capacity.

$\mathbf{P}$ hysical activity is important for metabolic and mental health in adults as well as in children (1-7). Schoolchildren should participate on a daily basis in 60 min or more of moderate to vigorous physical activity that is developmentally appropriate, enjoyable, and involves a variety of activities $(4,6,8)$. Unfortunately, the activity levels of children (and also adults) are decreasing in our Western industrialized countries (9-11), and more than $60 \%$ of the world's population does not engage in enough physical activity $(6,11)$. As if that were not enough, a study suggests (1) that those recommendations for daily activity were too low to reduce the clustered cardiovascular risk of children.

Regarding the seasonal change in daily activity, fewer data are available. In a recent review article (12) on accelerometerdetermined physical activity data in children, only four studies (13-16) with a longitudinal design were identified. All except one (14-16) reported on significant lower activity pattern during winter. Those findings were supported in other review articles $(12,17)$. However, whether that decrease in activity during winter was also associated with a reduction of exercise performance was not examined in the mentioned studies.

Therefore, this study aimed to compare the seasonal change in activity levels in children with their objective measured exercise performance obtained with a cardiopulmonary exercise test (CPET). Exercise capacity is positively associated with daily activity $(5,18,19)$, and peak oxygen uptake $\left(\mathrm{VO}_{2}\right)$, the gold standard measurement of exercise capacity, has also been shown to be of predictive value in apparently healthy adults (20), as well as in patients with several diseases (20-23).

\section{RESULTS}

At baseline examination (Table 1), children reported to be engaged in $10.6 \pm 4.1 \mathrm{~h}$ of sport per week. Boys were reported to be more active than girls $(P=0.004)$.

During winter, self-reported sporting activity decreased significantly to $8.5 \pm 4.3 \mathrm{~h} / \mathrm{wk}(P<0.001)$. In a detailed analysis (Table 2), hours of leisure sport activities $(P=0.002)$ declined from summer to winter and the hours in school sport $(P<0.001)$ declined, as a consequence of the fact that children reached a new school class. Activity from club sports remained unchanged from summer to winter $(P=0.700)$.

In parallel, $\mathrm{VO}_{2}$ declined from $102.0 \pm 17.5$ to $96.9 \pm 17.9 \%$ of predicted $(P<0.001)$, as did other parameters of exercise performance. As seen in Figure 1, this decline in $\mathrm{VO}_{2}$ was associated with the reduction in overall sporting activity $(r=$ 0.234; $P<0.032$ ).

\section{DISCUSSION}

This study showed, by way of a longitudinal design, that the exercise capacity of children was influenced by their seasonal activity, which was significantly lower during the winter months.

Many studies $(12,17)$, albeit almost all cross-sectional, report on the seasonal variation in the amount of daily activity in children. In concordance with our findings, the majority of the diminished activity occurred during the winter months. Girls were especially prone to be less active in comparison with boys. The reasons for reduced activity in winter might be multifactorial, but changes in weather, ecology, and hours of daylight, as well as periods of low temperatures, high rainfall, 


\section{Articles $\mid$ Müller et al.}

Table 1. Study subjects for anthropometric data, exercise performance, and self-reported sporting activity

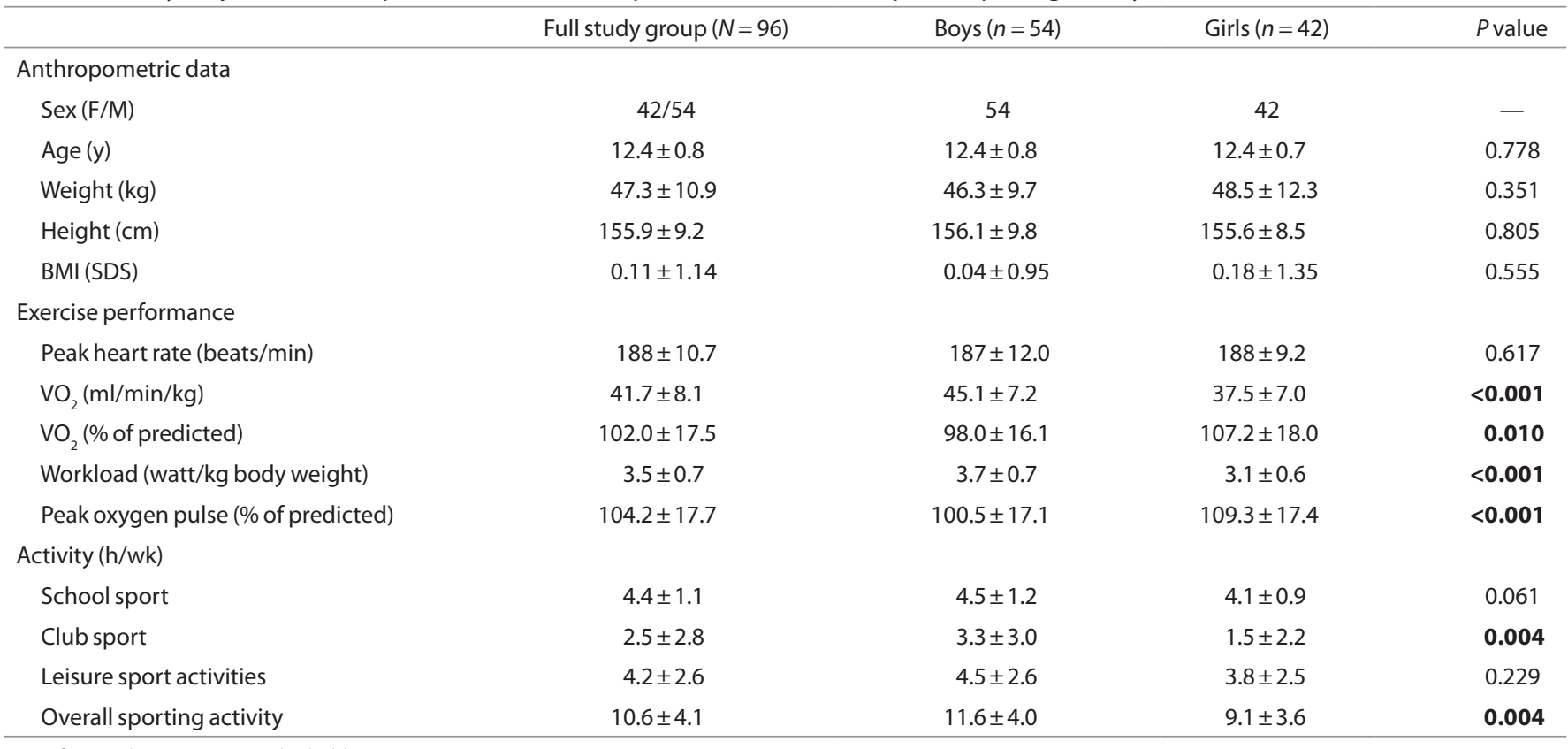

Significant values are presented in bold.

F, female; M, male; SDS, SD score; $\mathrm{VO}_{2}$, peak oxygen uptake.

Table 2. Children's characteristics according to the seasonal change in anthropometric data, exercise performance, and self-reported activity levels

\begin{tabular}{|c|c|c|c|c|}
\hline & $\begin{array}{c}\text { Baseline characteristics } \\
\text { estimated in summer } \\
\text { (May to July) }\end{array}$ & $\begin{array}{l}\text { Follow-up characteristics } \\
\text { estimated in winter } \\
\text { (March/April) }\end{array}$ & Seasonal change & $P$ value \\
\hline \multicolumn{5}{|l|}{ Anthropometric data } \\
\hline Age (y) & $12.4 \pm 0.8$ & $13.0 \pm 0.8$ & $+0.6 y$ & $<0.001$ \\
\hline Weight (kg) & $47.3 \pm 10.9$ & $51.7 \pm 11.9$ & $+4.4 \mathrm{~kg}$ & $<0.001$ \\
\hline BMI (SDS) & $0.11 \pm 1.14$ & $0.16 \pm 1.14$ & +0.05 & 0.155 \\
\hline \multicolumn{5}{|l|}{ Exercise performance } \\
\hline Peak heart rate (beats/min) & $188 \pm 10.7$ & $187 \pm 11.1$ & $\begin{array}{l}-1.2 \pm 10.5 \\
\text { beats } / \mathrm{min}\end{array}$ & 0.276 \\
\hline $\mathrm{VO}_{2}(\mathrm{ml} / \mathrm{min} / \mathrm{kg})$ & $41.7 \pm 8.1$ & $39.7 \pm 8.3$ & $-2.0 \mathrm{ml} / \mathrm{min} / \mathrm{kg}$ & $<0.001$ \\
\hline \multicolumn{5}{|l|}{ Activity (h/wk) } \\
\hline School sport & $4.4 \pm 1.1$ & $3.4 \pm 1.4$ & $-1 \mathrm{~h} / \mathrm{wk}$ & $<0.001$ \\
\hline Club sport & $2.5 \pm 2.8$ & $2.4 \pm 2.6$ & $-0.1 \mathrm{~h} / \mathrm{wk}$ & 0.700 \\
\hline Leisure sport activities & $4.2 \pm 2.6$ & $3.0 \pm 2.7$ & $-1.2 \mathrm{~h} / \mathrm{wk}$ & 0.002 \\
\hline Overall sporting activity & $10.6 \pm 4.1$ & $8.5 \pm 4.3$ & $-2.1 \mathrm{~h} / \mathrm{wk}$ & $<0.001$ \\
\hline
\end{tabular}

Significant values are presented in bold.

F, female; M, male; SDS, SD score; $\mathrm{VO}_{2^{\prime}}$ peak oxygen uptake.

strong winds, and snow contribute to this (12). Changing environmental conditions might reflect the significant reduction of leisure sport activities as seen in our cohort. The reduction in school sport is influenced by school policy. Children spend a longer time in school than in previous years, and physical education classes have been reduced over time $(6,11)$. Unfortunately for many children, school sports are essential for ensuring that a minimum of activity occurs. However, sport lessons are increasingly reduced with advancing school age. Our school policy is the reason why our cohort was $1 \mathrm{~h}$ 


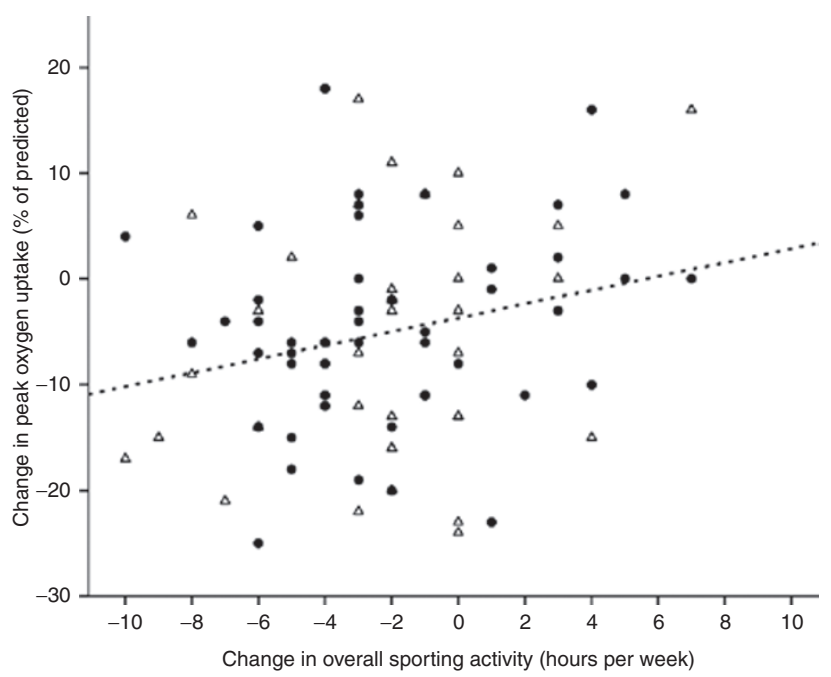

Figure 1. Seasonal change of peak oxygen uptake and overall sporting activity according to gender (solid circles represent boys; open triangles represent girls). The regression line shows that a reduction in overall sporting activity is associated with a decline in peak oxygen uptake $(r=0.234$; $P=0.032$ ).

less active in school during the winter. No seasonal influence could be observed in activities performed in a sports club. This was not surprising because club sport activities normally last throughout the year, and, for example, soccer, handball, and basketball were performed in a gym during winter.

Regarding reference values for the exercise performance, expressed as $\mathrm{VO}_{2}$, in children there are few studies published (24-26). Today, large-cohort data are not available for children. Furthermore, longitudinal exercise studies without intervention in healthy children are completely missing. Reports $(5,18)$ aiming to demonstrate a relation between daily activity and exercise performance have shown positive associations in children $(19,27)$. On the one hand, our findings confirm these positive associations of activity and exercise capacity. On the other hand, our data outline that there is also a dynamic change in exercise performance throughout the seasons. This reduction in exercise performance in winter was not only obvious in the absolute values of $\mathrm{VO}_{2}$, but also after correction of the data, which otherwise might be biased by children's natural development. However, we observed that the children had a normal development during the 6-mo period as there was no significant difference in the BMI SD scores. Therefore, the decline in $\mathrm{VO}_{2}$ during winter may be due to a decrease in stroke volume and/or a decrease in oxygen extraction at peak exercise.

It seems comprehensible that as the current review article (12) from Rich and colleagues concluded, there is sufficient evidence to support public health interventions that aim to increase physical activity during winter. Moreover, our findings now suggest that there might be a clinical relevance to enhancing physical activity during the winter because the exercise performance in children seems to be similarly altered. School-based lifestyle approaches should be the target to increase physical activity in children as is recommended by the European Association for Cardiovascular Prevention and Rehabilitation (6).

\section{Limitations}

There are only four studies, all from Europe (13-16), on the natural history of physical activity in children, and we do not know the longitudinal activity pattern from other geographic areas. Therefore, our results and conclusion cannot simply be transferred to other countries.

In this study, a nonstandardized questionnaire was used to assess the activity status of the children, although the goldstandard tool in assessing daily activity is the accelerometer. However, the children reported twice on their activity levels, and we can assume that the error in the first estimation of their activity status is similarly reproduced in the second assessment at the follow-up examination. Nevertheless, our findings should be verified in a study using accelerometer technique for activity measurement.

\section{Conclusion}

Enhancing physical activity in children during the winter might be important to maintaining their exercise capacity. Pilot school-based projects should facilitate this by compensating for the decline in leisure sport activity by increasing school sport during winter.

\section{METHODS}

\section{Study Subjects}

From May 2011 to April 2012, 96 children (42 girls, $12.4 \pm 0.8$ y) from two schools in Munich were included in the study. First, anthropometric data were recorded. BMI SD score was assessed using the German LMS percentiles from Kromeyer-Hauschild and colleagues (28). Afterward, children performed a CPET on a bicycle ergometer and filled in a comprehensive questionnaire wherein they had to report on their daily activity. Study subjects are displayed in detail in Table 1 according to gender.

The study was in accordance with the declaration of Helsinki (revision 2008) and was approved by the local ethical board (project no. $4027 / 11$ ). Subjects and their guardians gave written informed consent and agreed to the anonymous publication of their data.

\section{Exercise Capacity}

All the subjects underwent a symptom-limited CPET on a bicycle ergometer in the upright position according to the international guidelines (29).

In short, after a resting time of 2 min to define baseline, subjects had a 2-min warm-up without load, followed by a ramp-wise increase of load of 10,15,20, or $30 \mathrm{watt} / \mathrm{min}$ depending on the expected individual physical capacity estimated by the investigator. The aim was to reach a cycling duration of about 8-12 min after warm-up. The end of the CPET was marked by symptom limitation.

The exercise test featured a breath-by-breath gas exchange analysis using a metabolic chart (Geratherm Respiratory; Ganshorn Medical, Bad Neustadt a. d. Saale, Germany). $\mathrm{VO}_{2}$ was defined as the highest mean uptake of any 30-s time interval during exercise. Reference values for $\mathrm{VO}_{2}$ were drawn from Cooper and Weiler-Ravell (24) and expressed as percentage of predicted. Heart rate was measured continuously using a Polar RS800CX (Polar Electro, Kempele, Finland). Peak oxygen pulse was defined as $\mathrm{VO}_{2}$ divided by peak heart rate. The reference value was calculated from the $\mathrm{VO}_{2}$ reference value divided by the expected peak heart rate that was estimated to be “(220 - age $) \times 0.925$ " for bicycle testing according to Rhodes and colleagues $(30,31)$. 
Subjects with a respiratory exchange ratio $<1.06$ or a heart rate of $<85 \%$ of the predicted reference values calculated for bicycle testing (“( 220 - age $) \times 0.925$ ”) were excluded from the study.

\section{Activity Data}

Activity data were assessed by a questionnaire. Children were asked about the time (h/wk) they participate in school sport, in a sport club, and in leisure sport activity. Those three dimensions of sporting activities were additionally summed to calculate an overall sporting activity also displayed in h/wk.

\section{Data Analyses}

All descriptive data were expressed in mean values and SD score. $\mathrm{VO}_{2}$ was corrected for age, gender, and weight and expressed as percentage of predicted.

The comparison of anthropometric data, exercise performance, and self-reported sporting activity according to gender was performed by Student's $t$-test, whereas a paired $t$-test was used to compare baseline values with follow-up data. Associations of sporting activity and $\mathrm{VO}_{2}$ were assessed using Pearson's correlation and illustrated by a scatter plot according to gender.

All analyses were performed using PASW 19.0 software (SPSS, Chicago, IL). For all analyses, a two-tailed $P$ value $<0.05$ was considered to be statistically significant.

\section{ACKNOWLEDGMENTS}

We thank the "Willy-Brandt Schule" and the "Nymphenburger Schulen" in Munich for their cooperation in the study. We thank Lauren Steinman for proofreading the manuscript.

\section{STATEMENT OF FINANCIAL SUPPORT}

This study was funded by a grant from the Deutsche Herzstiftung e.V. (Frankfurt, Germany).

Disclosure: The authors declared no conflict of interest.

\section{REFERENCES}

1. Andersen LB, Harro M, Sardinha LB, et al. Physical activity and clustered cardiovascular risk in children: a cross-sectional study (The European Youth Heart Study). Lancet 2006;368:299-304.

2. Daniels SR, Arnett DK, Eckel RH, et al. Overweight in children and adolescents: pathophysiology, consequences, prevention, and treatment. Circulation 2005;111:1999-2012.

3. Pahkala K, Heinonen OJ, Simell O, et al. Association of physical activity with vascular endothelial function and intima-media thickness. Circulation 2011;124:1956-63.

4. Strong WB, Malina RM, Blimkie CJ, et al. Evidence based physical activity for school-age youth. J Pediatr 2005;146:732-7.

5. Thompson PD, Buchner D, Pina IL, et al.; American Heart Association Council on Clinical Cardiology Subcommittee on Exercise, Rehabilitation, and Prevention; American Heart Association Council on Nutrition, Physical Activity, and Metabolism Subcommittee on Physical Activity. Exercise and physical activity in the prevention and treatment of atherosclerotic cardiovascular disease: a statement from the Council on Clinical Cardiology (Subcommittee on Exercise, Rehabilitation, and Prevention) and the Council on Nutrition, Physical Activity, and Metabolism (Subcommittee on Physical Activity). Circulation 2003;107:3109-16.

6. Vanhees L, De Sutter J, GeladaS N, et al.; EACPR. Importance of characteristics and modalities of physical activity and exercise in defining the benefits to cardiovascular health within the general population: recommendations from the EACPR (Part I). Eur J Prev Cardiol 2012;19:670-86.

7. Perk J, De Backer G, Gohlke H, et al.; European Association for Cardiovascular Prevention \& Rehabilitation (EACPR); ESC Committee for Practice Guidelines (CPG). European Guidelines on cardiovascular disease prevention in clinical practice (version 2012). The Fifth Joint Task Force of the European Society of Cardiology and Other Societies on Cardiovascular Disease Prevention in Clinical Practice (constituted by representatives of nine societies and by invited experts). Eur Heart J 2012;33:1635-701.

8. U.S. Department of Health and Human Services, Office of Disease Prevention and Health Promotion. Healthy People 2010. (http://www.healthy people.gov.)
9. Riddoch CJ, Mattocks C, Deere K, et al. Objective measurement of levels and patterns of physical activity. Arch Dis Child 2007;92:963-9.

10. Troiano RP, Berrigan D, Dodd KW, Mâsse LC, Tilert T, McDowell M. Physical activity in the United States measured by accelerometer. Med Sci Sports Exerc 2008;40:181-8.

11. Knuth AG, Hallal PC. Temporal trends in physical activity: a systematic review. J Phys Act Health 2009;6:548-59.

12. Rich C, Griffiths LJ, Dezateux C. Seasonal variation in accelerometerdetermined sedentary behaviour and physical activity in children: a review. Int J Behav Nutr Phys Act 2012;9:49.

13. Bringolf-Isler B, Grize L, Mäder U, Ruch N, Sennhauser FH, Braun-Fahrländer C. Assessment of intensity, prevalence and duration of everyday activities in Swiss school children: a cross-sectional analysis of accelerometer and diary data. Int J Behav Nutr Phys Act 2009;6:50.

14. Nyberg G, Ekelund U, Marcus C. Physical activity in children measured by accelerometry: stability over time. Scand J Med Sci Sports 2009;19:30-5.

15. Rowlands AV, Pilgrim EL, Eston RG. Seasonal changes in children's physical activity: an examination of group changes, intra-individual variability and consistency in activity pattern across season. Ann Hum Biol 2009;36:363-78.

16. Mattocks C, Leary S, Ness A, et al. Intraindividual variation of objectively measured physical activity in children. Med Sci Sports Exerc 2007;39:622-9.

17. Carson V, Spence JC. Seasonal variation in physical activity among children and adolescents: a review. Pediatr Exerc Sci 2010;22:81-92.

18. Jackson AS, Beard EF, Wier LT, Ross RM, Stuteville JE, Blair SN. Changes in aerobic power of men, ages 25-70 yr. Med Sci Sports Exerc 1995;27:113-20.

19. Müller J, Hess J, Hager A. Daily physical activity in adults with congenital heart disease is positively correlated with exercise capacity but not with quality of life. Clin Res Cardiol 2012;101:55-61.

20. Myers J, Prakash M, Froelicher V, Do D, Partington S, Atwood JE. Exercise capacity and mortality among men referred for exercise testing. N Engl J Med 2002;346:793-801.

21. Dorn J, Naughton J, Imamura D, Trevisan M. Results of a multicenter randomized clinical trial of exercise and long-term survival in myocardial infarction patients: the National Exercise and Heart Disease Project (NEHDP). Circulation 1999;100:1764-9.

22. Myers J, Arena R, Dewey F, et al. A cardiopulmonary exercise testing score for predicting outcomes in patients with heart failure. Am Heart J 2008;156:1177-83.

23. Diller GP, Dimopoulos K, Okonko D, et al. Exercise intolerance in adult congenital heart disease: comparative severity, correlates, and prognostic implication. Circulation 2005;112:828-35.

24. Cooper DM, Weiler-Ravell D. Gas exchange response to exercise in children. Am Rev Respir Dis 1984;129(2 Pt 2):S47-8.

25. Washington RL, van Gundy JC, Cohen C, Sondheimer HM, Wolfe RR. Normal aerobic and anaerobic exercise data for North American schoolage children. J Pediatr 1988;112:223-33.

26. Ten Harkel AD, Takken T, Van Osch-Gevers M, Helbing WA. Normal values for cardiopulmonary exercise testing in children. Eur J Cardiovasc Prev Rehabil 2011;18:48-54.

27. Dencker M, Thorsson O, Karlsson MK, et al. Daily physical activity and its relation to aerobic fitness in children aged 8-11 years. Eur J Appl Physiol 2006;96:587-92.

28. Kromeyer-Hauschild K, Wabitsch M, Kunzem D, et al. Perzentile für den Body-mass-Index für das Kindes- und Jugendalter unter Heranziehung verschiedener deutscher Stichproben. Monatsschr Kinderheilkd 2001;149:807-18.

29. Gibbons RJ, Balady GJ, Bricker JT, et al.; American College of Cardiology/ American Heart Association Task Force on Practice Guidelines (Committee to Update the 1997 Exercise Testing Guidelines). ACC/AHA 2002 guideline update for exercise testing: summary article: a report of the American College of Cardiology/American Heart Association Task Force on Practice Guidelines (Committee to Update the 1997 Exercise Testing Guidelines). Circulation 2002;106:1883-92.

30. Rhodes J, Ubeda Tikkanen A, Jenkins KJ. Exercise testing and training in children with congenital heart disease. Circulation 2010;122: 1957-67.

31. Müller J, Böhm B, Semsch S, Oberhoffer R, Hess J, Hager A. Currently, children with congenital heart disease are not limited in their submaximal exercise performance. Eur J Cardiothorac Surg 2013;43:1096-100. 